\title{
THE ANTIULCER AND CYTOPROTECTIVE EFFECT OF AGERATUM CONYZOIDES-HONEY COMBINATION IN RATS
}

\author{
Fathihah B, Mahmood AA, Sidik K and Salmah I \\ Department of Molecular Medicine, Faculty of Medicine, University of Malaya, 50603 Kuala Lumpur
}

\begin{abstract}
Six groups of adult male Sprague Dawley rats, each consisting of six animals were used throughout the experiment. The gastroprotective effects of aqueous plant extract alone, honey alone or honey in combination with ethanolic or aqueous extracts of A. conyzoides and cimetidine were investigated in rats against ethanol-HClinduced gastric ulcer. Efficacy was assessed by determination of ulcer index and inhibition percentage. Oral administration of ethanol- $\mathrm{HCl}\left(5 \mathrm{ml} \mathrm{kg}{ }^{-1}\right.$ body weight) to fasted rats produced extensive lesions of gastric mucosa (Group 1). Pre-treatment with honey (2.5 g kg-1 body weight) alone (Group 2), aqueous plant extract alone (10\% w/v $5 \mathrm{ml} \mathrm{kg}^{-1}$ ) (Group 3), or honey in combination with each of alcoholic extract $(10 \% \mathrm{w} / \mathrm{w}$ $5 \mathrm{ml} \mathrm{kg}{ }^{-1}$ ) (Group 4), aqueous extract (10\% w/w $5 \mathrm{ml} \mathrm{kg}{ }^{-1}$ ) (Group 5) or cimetidine (10 $\mathrm{mg} / \mathrm{ml}$ honey $5 \mathrm{ml} \mathrm{kg}^{-1}$ ) (Group 6) orally 30 minutes before administration of absolute ethanol-HCl significantly $(p<0.05)$ protected gastric lesions by $46.74 \%, 61.50 \%$, $76.68 \%, 78.39 \%$ and $56.55 \%$ respectively. Although the mechanism of gastric protection is unknown, honey in combination with each plant extract appears to increase the resistance of gastric mucosal cells to the necrotizing effect of strong irritants in the absolute ethanol- $\mathrm{HCl}$ mixture. The results suggest that honey in combination with each plant extract might be beneficial in the treatment of a variety of diseases in which gastric mucosal injury is present. (JUMMEC 2003-2005; 8: 28-32)
\end{abstract}

KEYWORDS: Honey, A. conyzoides, cimetidine, rats, ulcer

\section{Introduction}

Ageratum conyzoides is a plant that is used for traditional herbal medicine in many countries especially in the tropical and subtropical region. A. conyzoides is very common in West Africa and some parts of Asia and South America. The plant is native to tropical America and has been introduced and naturalized in India ( $I$ ). The phytochemicals in A. conyzoides include alkaloids, cumarins, essential oils, flavonoids and tannins. It also consists of conyzorigum, chromene and flavones (2). Borthakor and Baruah found procene I and procene II in 1987 in a plant collected in India (3).

The formation of peptic ulcers depends on the presence of acid and peptic activity in gastric juice plus a breakdown in mucosal defences. There are two major factors that can disrupt the mucosal resistance to injury: non-steroidal anti-inflammatory drugs (NSAIDs) e.g. aspirin and Helicobacter pylori infection (4). As a matter of fact, many drugs were used to treat this disease but many of them cause adverse effects and recurrent infections frequently occur within a few weeks because of difficulty in eradication of $\mathrm{H}$. pylori (5).

Honey is a remarkable liquid, prepared by honeybees from the natural solutions called nectar obtained from various flowers (6). Honey consists of $70-80 \%$ of carbohydrates, which is the major constituent and various substances found in low amounts in honey are organic acid, proteins, amino acids, vitamins, enzymes, minerals and different other molecules such as pigments, flavonoids and antibacterial factors (7).

The curative properties of honey have been known since ancient times. The ancient Greeks, Romans, Chinese and Egyptians used honey to cure gut disease (8). The curing properties of honey for mankind were also clearly described in the Holy Quran (7). There is also a report that honey was able to induce adaptive cytoprotection against ethanol-induced gastric lesion in rats because of its high carbohydrate concentrations (7). 
Therefore, the present study was performed to evaluate the efficacy of cytoprotective properties of honey alone or in combination with each of alcoholic and aqueous plant extract of $A$. conyzoides and its antiulcer effect against experimental gastric ulcer in rats.

\section{Methods}

\section{Plant material}

A. conyzoides was collected at Faculty of Medicine, University of Malaya, Kuala Lumpur in the months of March to April 2004. The plant were identified and deposited at the Department of Pharmacy, Faculty of Medicine, University Malaya (Voucher No. 30).

\section{Preparation of aqueous and alcoholic extracts}

A. conyzoides fresh leaves were cut into small pieces, labeled, washed with distilled water and dried in an oven at $50^{\circ} \mathrm{C}$ for five to seven days until fully dried. The leaves were ground to a fine texture form using a grinder. The leaf powder was used for aqueous extraction and $95 \%$ ethanol extraction.

Forty grams of leaf powder was mixed with $800 \mathrm{ml}$ of sterile distilled water in a conical flask using a ratio of I:20. The mixture was then heated and stirred on a hotplate for three hours. After being left to cool, the residue was removed by filtration using a mesh and filter funnel. A rotary evaporator was used to extract the filtered material.

Forty grams of $A$. conyzoides powder was mixed with $800 \mathrm{ml}$ of $95 \%$ ethanol in a conical flask using a ratio of I:20.The flask was then covered with aluminium foil and left at room temperature $\left(25^{\circ} \mathrm{C}\right)$ for seven days. The residue was removed by filtration using a filter funnel, and the solvents were distilled under reduced pressure in an EYELA rotary vacuum evaporator until excess solvent evaporated.

Both extracts were then lyophilized in a freeze-dryer, to produce powdered forms of the extracts. Lyophilization removes the solvents from the solutes and stabilizes the formulation so that it can retain satisfactory pharmacological activity during long-term storage. The freeze-dried products were mixed with honey in a concentration of $100 \mathrm{mg}$ extract/gram of honey $(w / w)$.

\section{Honey}

Pure, unprocessed, unboiled commercial honey obtained from Faculty of Agriculture, University Putra Malaysia, Serdang, Selangor was used for the present study.
The oral pre-treatment applicant of honey alone or in combination with the plant extract was prepared. For the pre-treatment of honey alone $(5 \mathrm{ml} / \mathrm{kg}$ body weight), the honey was filtered before use and kept in room temperature to become homogenous. Pretreatment of aqueous extract alone $10 \%(\mathrm{w} / \mathrm{v})(5 \mathrm{ml}$ $\left.\mathrm{kg}^{-1}\right)$ was prepared. Meanwhile, for pre-treatment with honey in combination with aqueous extract of A. conyzoides, $(10 \% \mathrm{w} / \mathrm{w})\left(5 \mathrm{ml} \mathrm{kg} \mathrm{kg}^{-1}\right)$ was prepared. As for the preparation of working solution for pretreatment with honey in combination with ethanol extract of $A$. conyzoides, $(10 \% \mathrm{w} / \mathrm{w})\left(5 \mathrm{ml} \mathrm{kg} \mathrm{kg}^{-1}\right)$ was prepared. For the preparation of dose of drug used in pre-treatment with honey in combination with cimetidine, $10 \mathrm{mg} / \mathrm{l} \mathrm{ml}$ honey $\left(5 \mathrm{ml} \mathrm{kg}^{-1}\right)$ was used.

\section{Cimetidine}

This drug was obtained from the University of Malaya Medical Centre (UMMC), Kuala Lumpur. The drug's gastroprotective effect in combination with honey was to be determined.

\section{Experimental animals}

Experimental animals consisted of 36 healthy female Sprague Dawley rats. The rats were obtained from the animal house, Faculty of Medicine, University of Malaya. Sprague Dawley rats weighing between 200-225 grams were deprived of food for 48 hours, but they were allowed free access tap water until 17 hours before the experiment. They were housed in standard environmental conditions $\left(24^{\circ} \mathrm{C}, 60-70 \%\right.$ humidity $)$ under natural lighting. During the fasting period, the animals were placed individually in cages with wide-mesh wire bottoms to prevent coprophagy. On the day of the experiment, the rats were divided into five groups and were assigned to different control and treatment groups. $1.0 \mathrm{ml}$ of distilled water was given orally to each rat in Group I (ulcer control). Meanwhile, for Group 2 (honey alone), $1.0 \mathrm{ml}$ of honey was given to each rat. Each treated rat in Group 3, received $1.0 \mathrm{ml}$ of honey in combination with aqueous extract of A. conyzoides whereas $1.0 \mathrm{ml}$ of honey in combination with ethanol extract of $A$. conyzoides was administered orally to each treated rat in Group 4. For the animals in Group 5, each of them received $1.0 \mathrm{ml}$ of honey in combination with cimetidine.

Thirty minutes after their pre-treatment, the rats were administered with $1.0 \mathrm{ml}$ of absolute ethanol$\mathrm{HCl}(5 \mathrm{ml} / \mathrm{kg}$ body weight) to induced ulceration except for the rats in Group I, where they received the same amount of distilled water by the same route.

They were killed 30 minutes later under anaesthesia, using diethyl ether. Their stomachs were rapidly 
removed after ligating both the oesophageal and pyloric ends. The stomach of each rat was excised and opened along the greater curvature.

\section{Gross lesion evaluation}

The stomachs were inflated with $10 \mathrm{ml}$ of $1 \%$ buffered formalin to fix the outer layer of the stomachs. After rinsing with normal saline, the mucosa of the stomach was examined under a dissecting microscope with a square-grid eyepiece to assess the formation of ulcers (haemorrhagic lesions). The sum for the number of gastric lesions for each stomach was used as ulcer index (UI) and the inhibition percentage was calculated by the following formula:

$$
\begin{aligned}
\text { Inhibition } \%= & {[(U \mathrm{I} \text { control }-\mathrm{UI} \text { treated }) /} \\
& \text { Ul control }] \times 100
\end{aligned}
$$

\section{Statistical analysis of data}

Results are expressed as means \pm S.E.M.The statistical difference between the mean ulcer index of the positive control and negative control, and the mean ulcer index of the treated group and positive control, both were calculated by using Student's t-test, SPSS for Windows Student Version II.0.

\section{Histopathology}

The stomachs were fixed in freshly made 10\% buffered formalin for four to six hours. Next, they were processed in an automated machine (TISSUE PROCESSOR LEICA TP 1020). Then, the biopsies were embedded in paraffin and sectioned (3-5 $\mu \mathrm{m})$, and were stained with haematoxylin and eosin. Then the sections were analyzed using a light microscope.

\section{Results}

The results of the present study are summarized in Table I. The findings of this study showed that rat mucosa gastric injury induced by absolute ethanol$\mathrm{HCl}$ was significantly reduced by ethanol extract of A. conyzoides in combination with honey as well as its aqueous extract.

Administration of absolute ethanol- $\mathrm{HCl}$ resulted in severe gastric damage. Thick reddish-black lines visible from outside indicate the formation of severe haemorrhagic lesions. After opening the stomach, lesions were found in the mucosa. They were located mostly in the corpus (the portion of the stomach secreting acid and pepsin). No haemorrhagic lesions developed in the forestomach (the non-secretory part of the stomach) due to the presence of squamous epithelium that coated the forestomach. The stomach rugae were almost flattened.
The result was substantiated by histopathological findings. Histology analysis of all rats treated with absolute ethanol- $\mathrm{HCl}$ revealed the tremendous infiltration of polymorphonuclear leucocytes in the mucosa up to submucosa region. There was a complete destruction of mucosa, which indicated severe haemorrhagic lesions formation. The depth of the ulcer extended up to the muscularis mucosae. The submucosa was markedly thickened by oedema.

Pre-treatment with ethanol and aqueous extract of A. conyzoides in combination with honey, very mild gross lesions were visible. The gross section of stomach of rats treated with ethanol extract of A. conyzoides showed only mild congestion compared to the stomachs of rats treated with aqueous extract of the plant, otherwise the stomach appearance was normal. In histopathologically findings, they were found to inhibit the absolute ethanol- $\mathrm{HCl}$ induced necrosis, congestion, haemorrhage and oedema in gastric mucosa.

Grossly, the stomach of the cimetidine in combination with honey $(10 \mathrm{mg} / \mathrm{rat} / \mathrm{l} \mathrm{ml}$ honey) resulted in less formation of gastric lesions compared to ulcer control. Histologically, it showed superficial erosion in the mucosa and a moderate degree of oedematous submucosa with less neutrophilic infiltration in the submucosa.

Pre-treatment with honey alone resulted in grossly moderate presence of haemorrhagic lesions. In histopathological finding, there was moderate erosion of gastric mucosa with necrotic patches and moderate gastric oedema with infiltration of neutrophils in the submucosa. Pre-treatment with aqueous plant extract also reduced the haemorrhagic lesions of mucosa grossly and histologically compared to ulcer control.

\section{Discussion}

The ethanol and aqueous extract of $A$. conyzoides in combination with honey exhibited marked cytoprotection in absolute ethanol- $\mathrm{HCl}$ induced rats by increasing gastric mucosal content through its phytochemical constituent, flavonoids which possess antioxidant activity. Ethanol has been shown to produce free radicals and induce peptic ulcers (4).

Earlier studies verified that antioxidants play a major task in protection of cellular damage by scavenging free radicals. The flavonoids kaempferol and quercetin are the constituents in A. conyzoides that are known to possess antioxidant activity (9). They act by increasing the gastric mucosal content, which is accompanied by 
Table I. Effect of A. conyzoides on induction of gross lesions in the absolute ethanol- $\mathrm{HCl}$ induced gastric ulcer model

\begin{tabular}{|c|c|c|c|c|c|}
\hline Group & Treatment & $\begin{array}{l}\text { No. of } \\
\text { Rats }\end{array}$ & $\begin{array}{l}\text { Dose } \\
\text { Orally }\end{array}$ & $\begin{array}{c}\text { Ulcer Index } \\
(\text { Mean } \pm \text { S.E.M) }\end{array}$ & $\begin{array}{c}\text { Inhibition } \\
(\%)\end{array}$ \\
\hline 1 & $\begin{array}{l}\text { Absolute ethanol-HCL } \\
\text { (ulcer control) }\end{array}$ & 6 & $5 \mathrm{ml} \mathrm{kg}^{-1}$ & $1194.83 \pm 78.352$ & 0 \\
\hline 2 & Honey alone & 6 & $5 \mathrm{ml} \mathrm{kg}^{-1}$ & $636.33 \pm 29.7 I^{*}$ & 46.74 \\
\hline 3 & $\begin{array}{l}\text { Aqueous extract } \\
\text { A. conyzoides only }\end{array}$ & 6 & $5 \mathrm{ml} \mathrm{kg}^{-1}$ & $460 \pm 18.62^{*}$ & 61.50 \\
\hline 4 & $\begin{array}{l}\text { Aqueous extract } \\
\text { A. conyzoides + Honey }\end{array}$ & 6 & $5 \mathrm{ml} \mathrm{kg}^{-1}$ & $278 \pm 13.02^{* *}$ & 76.68 \\
\hline 5 & $\begin{array}{l}\text { EtOH extract } \\
\text { A. conyzoides + Honey }\end{array}$ & 6 & $5 \mathrm{ml} \mathrm{kg}^{-1}$ & $258 \pm 16.67^{* *}$ & 78.40 \\
\hline 6 & Cimetidine + Honey & 6 & $5 \mathrm{ml} \mathrm{kg}^{-1}$ & $519.17 \pm 15.60^{* *}$ & 56.55 \\
\hline
\end{tabular}

a proportionate increase in protein and hexosamine. Hence, they inhibit gastric damage (I0) and (II). A recent review bears out those flavonoids are good anti-inflammatory agent and are furthermore able to shield gastric mucosa against a variety of ulcerogenic agents via several mechanisms predominantly freeradical scavenging and antioxidant properties, enhance mucus production, anti-secretory action and inhibition of the $H$. pylori progression (I).

Regulation of gastric acid secretion involves $\mathrm{Ca}^{2+}$ ion. $\mathrm{Ca}^{2+}$ ions also mediate free radical generation in peptic ulcers. As a consequence $\mathrm{Ca}^{2+}$ channel blockers like nifedepine and verapamil are needed to restrain the $\mathrm{Ca}^{2+}$ ion activity $(12)$. There has been a report that crude extract of $A$. conyzoides can possess $\mathrm{Ca}^{2+}$ channel blocking activity comparable to verapamil (13). Therefore, it can be hypothesized that the $\mathrm{Ca}^{2+}$ channel blocking activity of $A$. conyzoides may contribute towards its cytoprotective effect.

A. conyzoides belongs to the Asteraceae family. Polysaccharides are a main constituent of the Asteraceae family, which holds many therapeutic properties of the plants under this family. Alginic acid, which is categorized as heterogeneous polysaccharide are believed to be effective in treating gastric ulcer. Alginic acid was suggested to form gel layer and acts as barrier against excessive $\mathrm{pH}$ and thus protects gastric mucosa (14). It is speculated that the polysaccharide constituent contributes to the production of cytoprotective effect in A. conyzoides.
As for honey, it seems to share with sucralfate a common mechanism of action, indicating the presence of 'sucralfate-like' substances in honey, which afford the protection to gastric mucosa. Moreover, presence of catalase that possesses the antioxidant properties prevents formation of gastric ulcer (15). High concentration of carbohydrates honey behave as mild irritants that can induce adaptive cytoprotection (7). Meanwhile, cimetidine is an acid suppressant, which functions to inhibit the secretion of gastric acid and thus lead to diminishing ethanol-induced gastric damage.

\section{Conclusion}

This study demonstrated that honey and A. conyzoides attenuates gastric lesion and mucosal injury induced by absolute ethanol- $\mathrm{HCl}$ by increasing gastric mucosal content. Further work is necessary to isolate active principles and clarify the actual mechanism concerned in the anti-ulcer activity of this plant and to explore the active ingredients that are responsible for the protective effects of honey.

\section{References}

I. Shirwaikar A, Bhilegaonkar PM, Malini S, et al. The gastroprotective activity of the ethanol extract of Ageratum conyzoides. Journal of Ethnopharmacol 2003; 86(I): II7-I2I. 
2. Vyas AS, Mulchandani NB. Polyoxygenated flavones from Ageratum conyzoides. (abstract). Phytochemistry 1986; 25(I I):2625.

3. Borthakor N, Baruah AKS. Search for precocenes in Ageratum conyzoides Linn. Of North-East India. J Indian Chem Soc 1987; (64):580-58I.

4. Soll AH. Pathogenesis of Peptic Ulcer and Implications from Therapy. N Engl J Med 1990; (322):909-916.

5. Chan FKL, Leung WK. Peptic Ulcer Disease. Lancet North Am Ed 2002; (360):933-94I.

6. Subrahmanyam M. Topical application of honey in the treatment of burns. Br J Surg 1991; 78:497-8.

7. Gharzouli K, Gharzouli A, Amira S, et al. Prevention of ethanol-induced gastric lesions in rats by natural honey and glucose-fructose-sucrose-maltose mixture. Pharmacol Res 1999; 2(39): 15I-56.

8. Zumla A, Lulat A. Honey: a remedy rediscovered (Editorial). J R Soc Med 1989; 82:384-385.

9. Halliwell B. Free radical, antioxidant and human disease: curiosity, cause or constipation? (abstract). Lancet 1994; 334:72I.
10. Alarcon DLLC, Martin MJ, Lacasa C, et al. Antiulcerogenic activity of flavonoids and gastric protection. J Ethnopharmacol 1994; (42): I6I-70.

II. Parmar NS, Parmar S. The antiulcer potential of flavonoids (abstract). Indian J Physiol and Pharmacol 1998; 343-5I.

12. Mandal S, Roy RK, Das HN, et al. Potentiation of gastric antiulcer effect of famotidine by calcium channel blockers in rats (abstract). Indian J of Physiol Pharmacol 1998; 30:390.

13. Achola KJ, Munenge RW. Activity of Ageratum conyzoides on isolated rat phrenic nerve diaphragm and blood pressure on anaesthetized rats (abstract). Int J Pharm 1997; 35:31.

14. Wiart C. Medicinal Plants of Southeast Asia. Kuala Lumpur: Pelanduk Publications; 2000.

15. Ali ATMM, Al-Swayeh OA. Natural honey prevents ethanol-induced increased vascular permeability changes in the rat stomach.J Ethnopharmacol 1997; (55):23 I-238. 